\title{
META-ANALYSIS OF THE GENETIC FACTORS THAT PREDISPOSED ASIAN WOMEN TO GESTATIONAL DIABETES MELLITUS
}

\author{
SHARIFAH NURDIYANA SYED MOHD BAHKTIAR ${ }^{1}$, MUHAMMAD HISYAM \\ JAMARI ${ }^{1}$, NURUL AISHAH WAN NOOR ${ }^{2}$, RABIA'TUL A'DAWIYAH ARIFF \\ FADZILAH $^{2}$, MUHAMAD ZAFRI ABDUL KARIM ${ }^{2}$, HAIZATUL HUSNA ABDUL \\ HALIM $^{2}$, NOOR FATIHAH ABU ${ }^{2}$, TEH LAY KEK ${ }^{1,2}$ AND MOHD ZAKI SALLEH ${ }^{1,2^{*}}$ \\ ${ }^{1}$ Integrative Pharmacogenomics Institute (iPROMISE), UiTM Selangor Branch, Puncak \\ Alam Campus, Selangor, Malaysia \\ ${ }^{2}$ Faculty of Pharmacy, UiTM Selangor Branch, Puncak Alam Campus, Selangor, Malaysia
}

Published online: 23 November 2021

To cite this article: SHARIFAH NURDIYANA SYED MOHD BAHKTIAR, MUHAMMAD HISYAM JAMARI, NURUL AISHAH WAN NOOR, RABIA'TUL A'DAWIYAH ARIFF FADZILAH, MUHAMAD ZAFRI ABDUL KARIM, HAIZATUL HUSNA ABDUL HALIM, NOOR FATIHAH ABU, TEH LAY KEK \& MOHD ZAKI SALLEH (2021) Meta-analysis of the genetic factors that predisposed Asian women to gestational diabetes mellitus, Malaysian Journal of Pharmaceutical Sciences, 19(2): 131-152. https://doi.org/10.21315/mjps2021.19.2.9

To link to this article: https://doi.org/10.21315/mjps2021.19.2.9

\begin{abstract}
A meta-analysis was conducted to determine the significant risk alleles which increase the risks of gestational diabetes mellitus (GDM) in Asian to help in decision-making for genotyping of women at risk. PubMed, Science Direct and HuGE navigator were used to identify relevant studies from January 2000 to November 2018. Data extraction was done by five reviewers. Using Review Manager 5.3, association between 11 SNPs and risks of GDM was determined. Odds ratios (ORs) with 95\% confidence intervals (95\% Cl), test of heterogeneity and publication bias were calculated. The result was considered significant if $p$-value $\leq 0.05$. Twenty-one studies were identified based on the inclusion and exclusion criteria. From 11 genetic variants studied, 9 were found to have significant association with GDM susceptibility with different heterogeneity. Allelic, dominant and recessive genetic models show MTNR1B (rs138753, rs10830963) and CDKAL1 (rs7754840) are significantly associated with GDM. IGF2BP2 (rs4402960) was found to have significant association with GDM using allelic and recessive models. For TCF7L2 (rs7903146), significant association was found using allelic, dominant and over dominant models. KCNQ1 (rs2237892) showed association with GDM in dominant model only. Strong associations with increased susceptibility for GDM were also found for GSTM1 (deletion), GSTT1 (deletion) and GSTP1 (rs1695). However, MTNR1B (rs10830962) and PPARY2 are lack of association with GDM risk in Asian population. Nine genetic variants were associated with increased GDM risk in Asian population. Screening of these polymorphisms to identify pregnant women at risk is recommended for prevention and personalised intervention.
\end{abstract}

"Corresponding author: zakisalleh.ipromise@gmail.com

(c) Penerbit Universiti Sains Malaysia, 2021. This work is licensed under the terms of the Creative Commons Attribution (CC BY) (http://creativecommons.org/licenses/by/4.0/). 
Keywords: Gestational diabetes mellitus, Single nucleotide polymorphism, Odds ratio, Confidence interval, Meta-analysis

\section{INTRODUCTION}

Gestational diabetes mellitus (GDM) is commonly known as hyperglycaemia during pregnancy. Malaysia reported a prevalence of $18.3 \%$, one of the countries in the South East Asia with the highest prevalence of GDM (Zhu and Zhang, 2016). A local study by Logakodie et al. (2017) reported an alarming rate of GDM at $27.9 \%$ in 2017 , compared to $9 \%-12 \%$ in 2007 (Tan, Ling and Omar 2007).

Diagnosis of GDM mainly follows the guidelines by American Diabetes Association (ADA) or International Association of Diabetes and Pregnancy Study Groups (IADPSG), using oral glucose tolerance test (OGTT) at around 24-28 weeks of gestation or as early as possible in women with high risk of GDM. The risk factors for GDM include age $\geq 25$ years old, body mass index $(\mathrm{BMI}) \geq 27 \mathrm{~kg} / \mathrm{m}^{2}$, first degree relative with diabetes mellitus (DM), history of macrosomia, bad obstetric history and persistent glycosuria. Although OGTT is the cornerstone for the diagnosis of GDM, few studies had challenged its use for GDM diagnosis. Some researchers suggested the use of other tests or parameters for the diagnosis and identification of risks for GDM, such as haemoglobin A1c (HbA1c), other biomarkers and genetic tests (Rodrigo and Glastras 2018). Rapid advances and cost reductions of sequencing technologies, coupled with the completion of Human Genome Project, had made possible to identify regions of the genome harbouring susceptibility genes (Watanabe et al. 2007).

Single nucleotide polymorphisms (SNPs) which have been identified to increase the risks of developing diabetes mellitus type 2 (DM2) include MTNR1B, TCF7L2, HHEX/IDE, FTO and NOTCH2 (Beer and Mccarthy 2014). Due to the similar underlying mechanisms of DM2 and GDM, researchers hypothesise that DM2 and GDM shared the genetic variants that increase the susceptibility (Lauenborg et al. 2009; Stuebe et al. 2014). However, most of the studies were conducted on the European and Caucasian population (Lowe et al. 2016). Up to date, only one genome-wide association study (GWAS) have been done in Asians (Kwak et al. 2012). Other studies involving Asian were done in smaller sample size and fewer genetic variants. Hence, this meta-analysis was done by combining these studies of small sample size to determine the genetic factors that predisposed Asian women to GDM.

\section{METHODS}

\section{Literature Search Strategy}

A comprehensive literature search was carried out for related articles available in PubMed, Science Direct and HuGE navigator databases, which were published from January 2000 to November 2018. The search strategy consisted of queries of multiple combination 'gestational diabetes mellitus', 'GDM' and 'genetic polymorphisms', with names of specific genes combined with the search term 'gestational diabetes mellitus'. The search was focused on studies that had been conducted in the Asian women. Only articles in English language were included.

Malay J Pharm Sci, Vol. 19, No. 2 (2021): 131-152 


\section{Eligible Studies and Selection Criteria}

The candidate studies were based on these major inclusion criteria: a) original casecontrol study, b) population must be pregnant Asian women, c) identification of GDM using the criteria of ADA, Implementation of the IADPSG or other standard diagnostic criteria, d) associations between the genetic polymorphisms and GDM which were assessed in two or more independent studies, e) the subjects were in 24 to 28 gestational periods, and f) the age of the GDM subjects were above 18 years old and below 50 years old. The major reasons for exclusion of studies were: a) duplicates, b) studies with insufficient data, c) meta-analysis or review articles and d) family-based studies.

\section{Data Extraction}

Five independent reviewers screened the titles and abstracts of all the articles identified from the literature search. Irrelevant articles were eliminated. The reviewers also assessed the articles for the inclusion and exclusion criteria. Discrepancies and inconsistencies of results during the assessment were resolved through consensus. The following information were independently extracted by the reviewers: author, year of publication, ethnicity, study design, mean age for cases and controls, the numbers of case and control group for each genotype, genotyping method and the criteria whereby GDM is confirmed. Control groups generally follows the criteria of case group. However, three studies included in this metaanalysis used general population to represent control group, with strict criteria: age $\geq 50$ years old with no history of DM2, no first degree relative with DM2, with fasting plasma glucose level $<6.1 \mathrm{mmol} / \mathrm{L}$ and $\mathrm{HbA} 1 \mathrm{c}$ level $<6.0 \%$. Thus, the control group was expected to have a low risk for DM2.

\section{Statistical Analysis}

Statistical analysis was carried out with Mantel-Haenszel statistics using Review Manager (RevMan) 5.3 statistical software (Cochrane Collaboration, Oxford, England). The allele frequency for each single nucleotide polymorphism (SNP) or the genotype frequency for each case and control groups was used for calculation of odds ratios (OR) and their corresponding $95 \%$ confidence interval $(\mathrm{Cl})$. OR $\geq 1$ shows association of the allele or genotype with the increased risk for GDM. The $Z$ test $(p<0.05)$ was used to determine the significance of the pooled OR. Heterogeneity across individual studies was assessed by $I^{2}$ and Cochrane $Q$ statistics to ensure that each group of studies was suitable for meta-analysis. Heterogeneity describes the percentage of variation across studies that is due to heterogeneity rather than chance. For this meta-analysis, $I^{2}<50 \%$ shows that the heterogeneity of the studies is acceptable, while $\mathrm{I}^{2}>50 \%$ shows serious heterogeneity and thus, the results obtained must be interpreted with caution. Fixed effect model was used for $\mathrm{I}^{2}<50 \%$, while random effect model was used for $\mathrm{I}^{2}>50 \%$. Meanwhile, the genetic models used in this study include dominant, recessive, over-dominant, and allelic models. Supposed that the alleles of the gene of interest are A and B, whereby A is the 'variant' or 'risk' allele and $B$ is wild-type allele, the dichotomisation of the SNP genotypes are as follows: Dominant ( $A A+A B$ versus $B B$ ); Recessive ( $A A$ versus $A B+B B)$; Over Dominant ( $A B$ versus $A A+B B$ ) and Allelic ( $A$ versus $B$ ). The best model was selected to represent the result of association of the SNPs with increased risk for GDM. Genetic variant with 
significant association to increased risk of GDM but with high heterogeneity was subjected to subgroup analysis. Funnel plots were used to assess the potential publication bias and sensitivity test was done to assess the robustness of the results.

\section{RESULTS}

\section{Characteristics of Studies}

We initially identified 41 eligible studies based on the inclusion and exclusion criteria outlined. However, many SNP candidates were present in only one study, rendering the data insufficient and cannot be compared. Thus, twenty studies were further excluded. Finally, 21 studies with a total of 19,577 GDM cases and 24,788 controls, involving 11 SNPs were included. The flow of study selection is shown in Figure 1. In the control groups of the population studies, the polymorphisms of these genetic variants were consistent with Hardy-Weinberg equilibrium. The characteristics of the studies are shown in Table 1. Results of analysis with respect to genetic models are listed in Table 2. Figure 2 shows the forest plots of the genetic association studies.

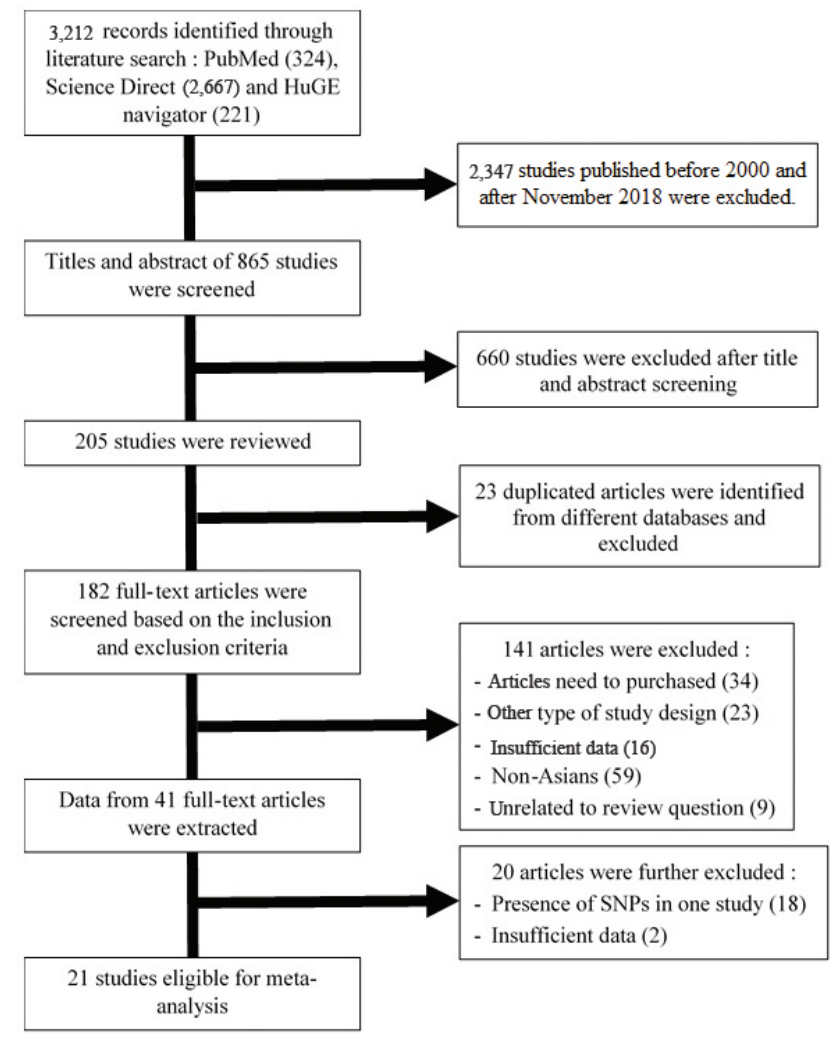

Figure 1: Selection process for the studies included in meta-analysis.

Malay J Pharm Sci, Vol. 19, No. 2 (2021): 131-152 


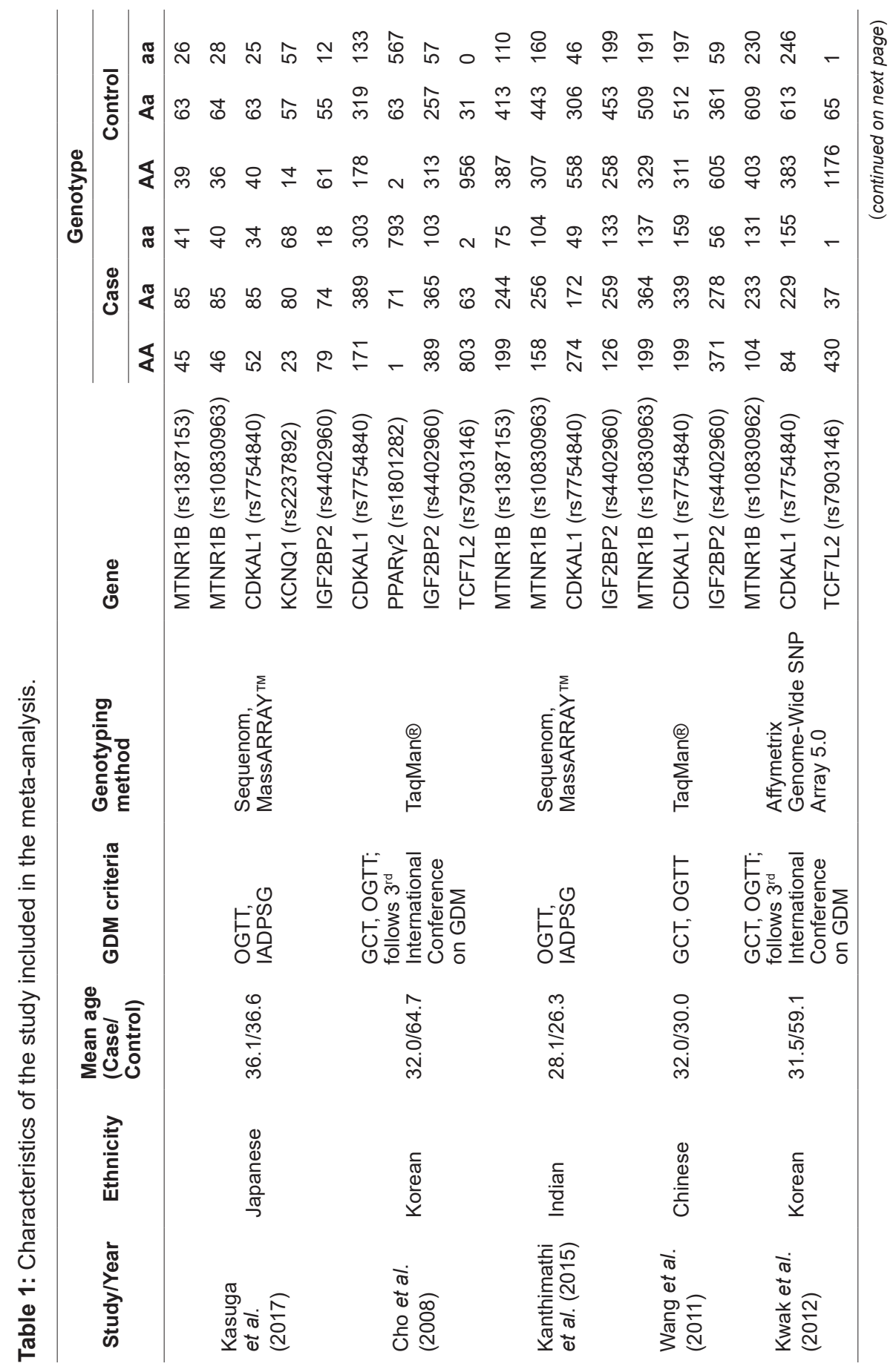

Malay J Pharm Sci, Vol. 19, No. 2 (2021): 131-152 


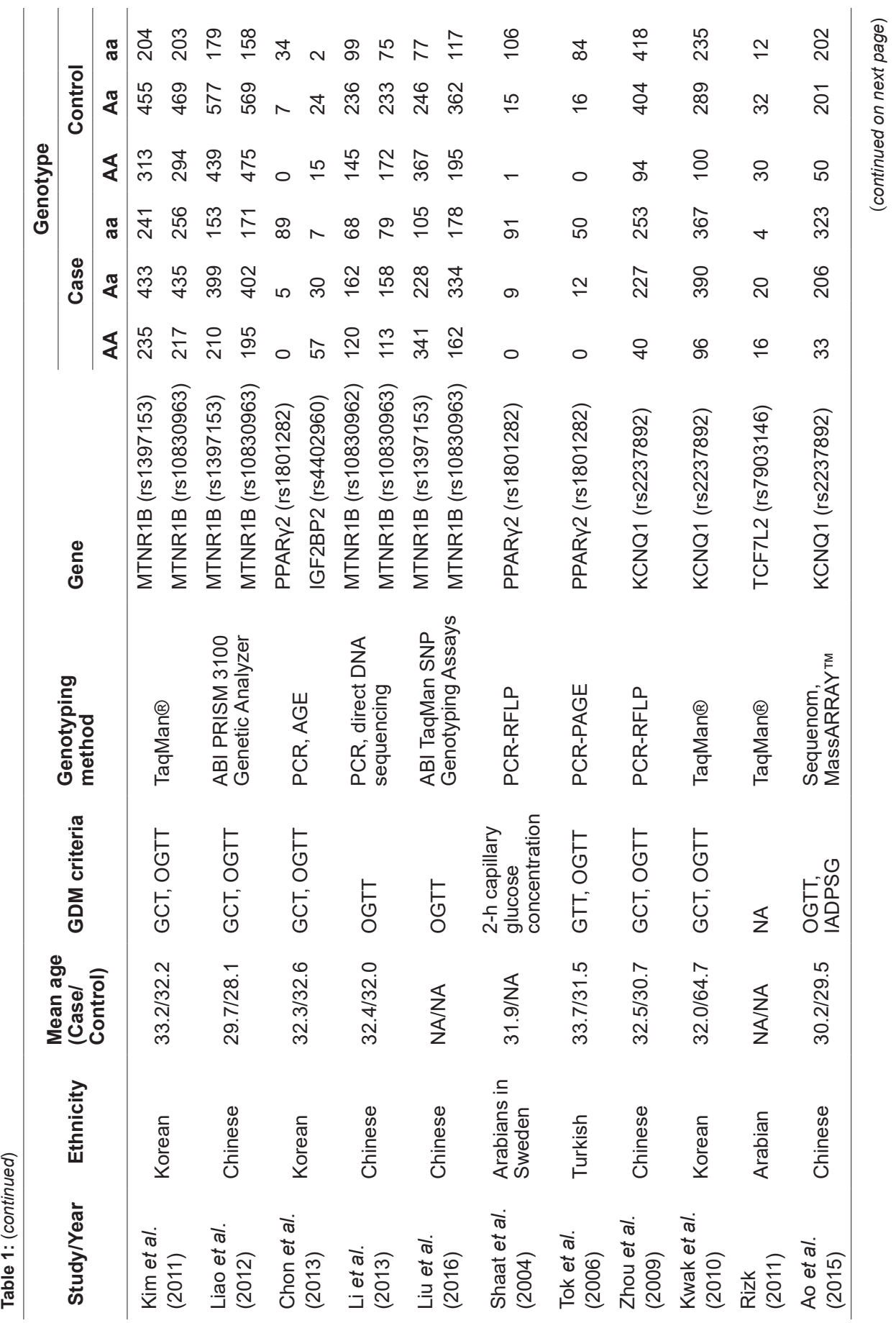

Malay J Pharm Sci, Vol. 19, No. 2 (2021): 131-152 


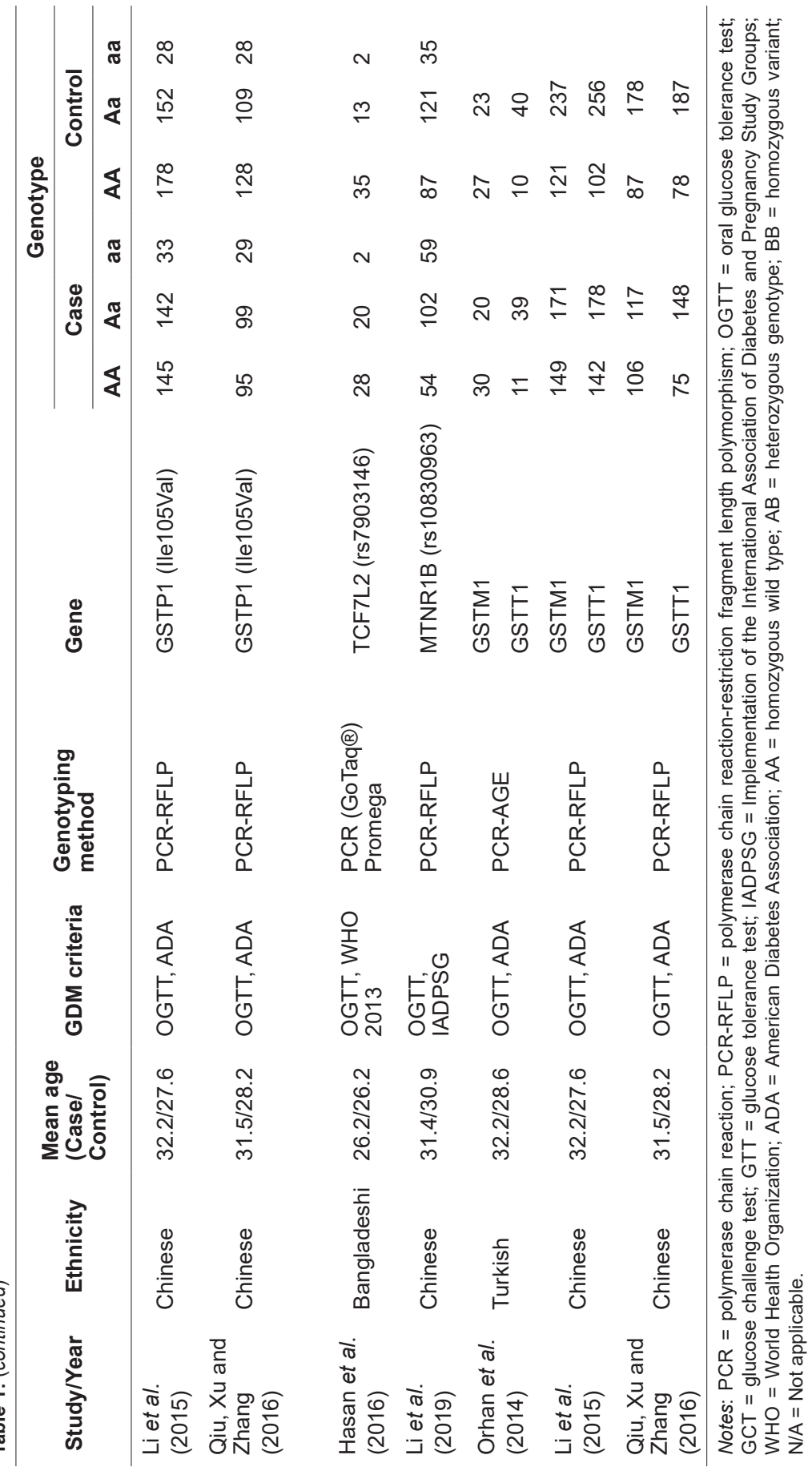

Malay J Pharm Sci, Vol. 19, No. 2 (2021): 131-152 


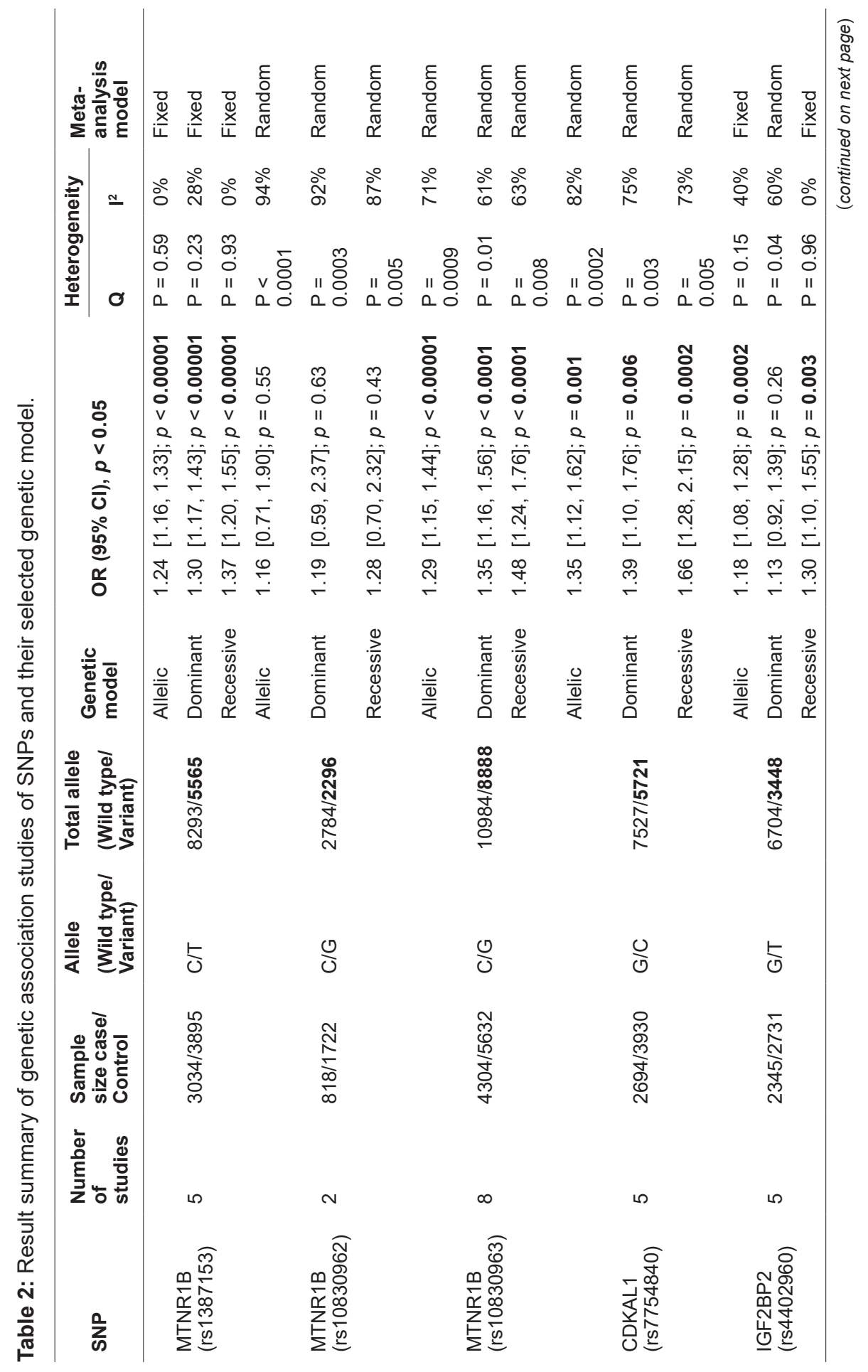

Malay J Pharm Sci, Vol. 19, No. 2 (2021): 131-152 


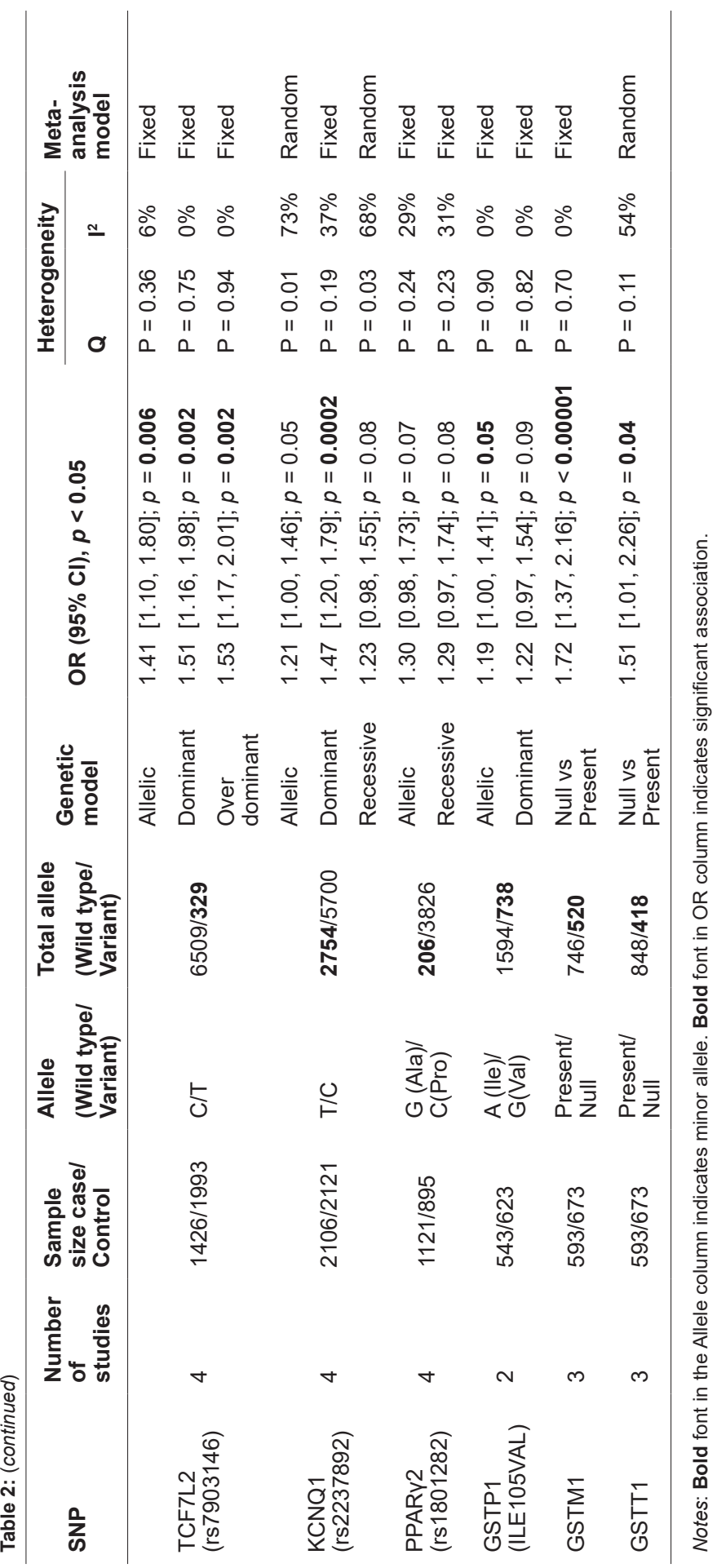

Malay J Pharm Sci, Vol. 19, No. 2 (2021): 131-152 

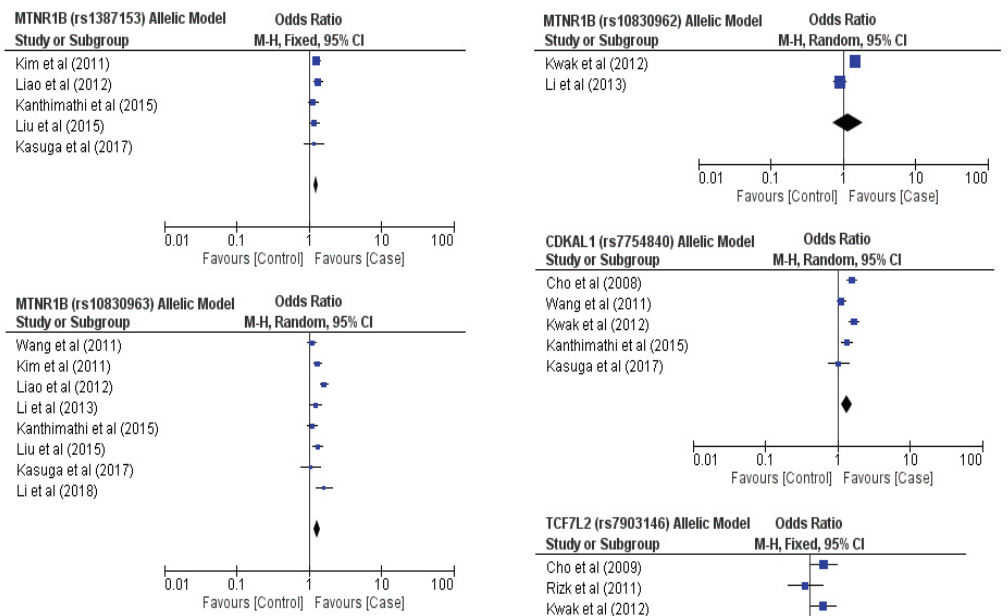

TCF7L2 (rs7903146) Allelic Model Odds Ratio
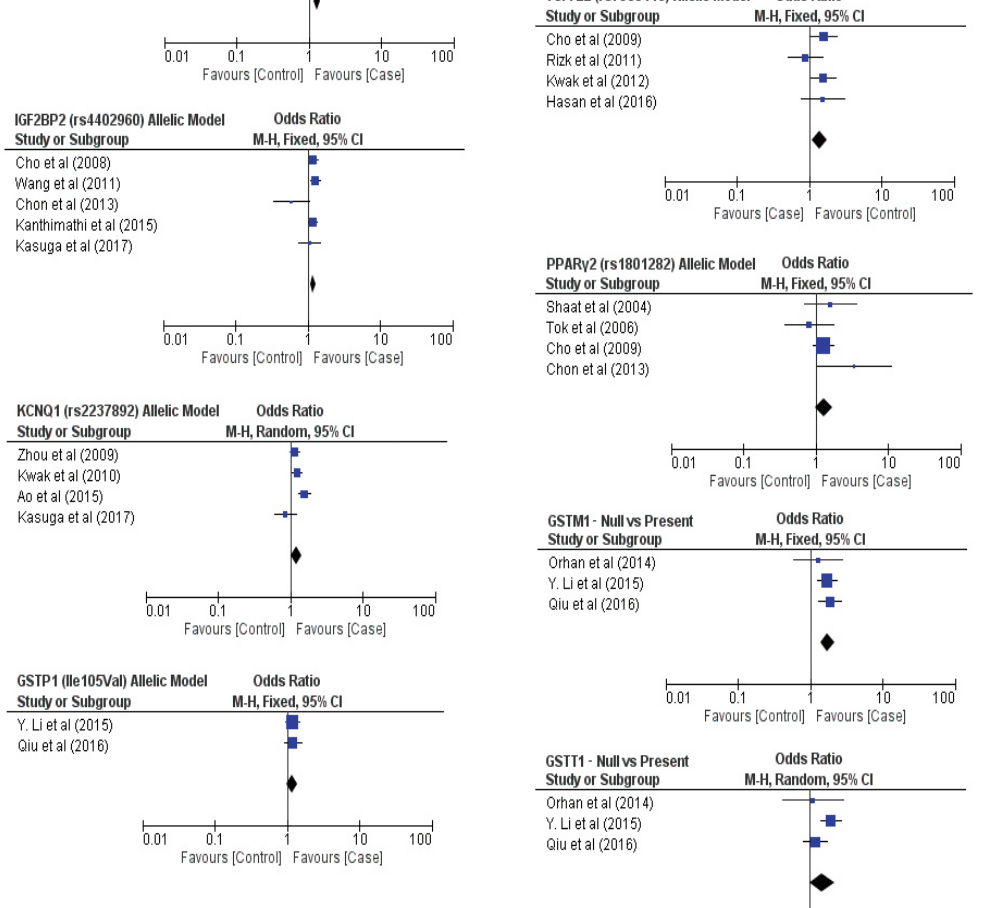

Figure 2A: Forest plot for genetic association of GDM using different genetic models (Allelic model). 

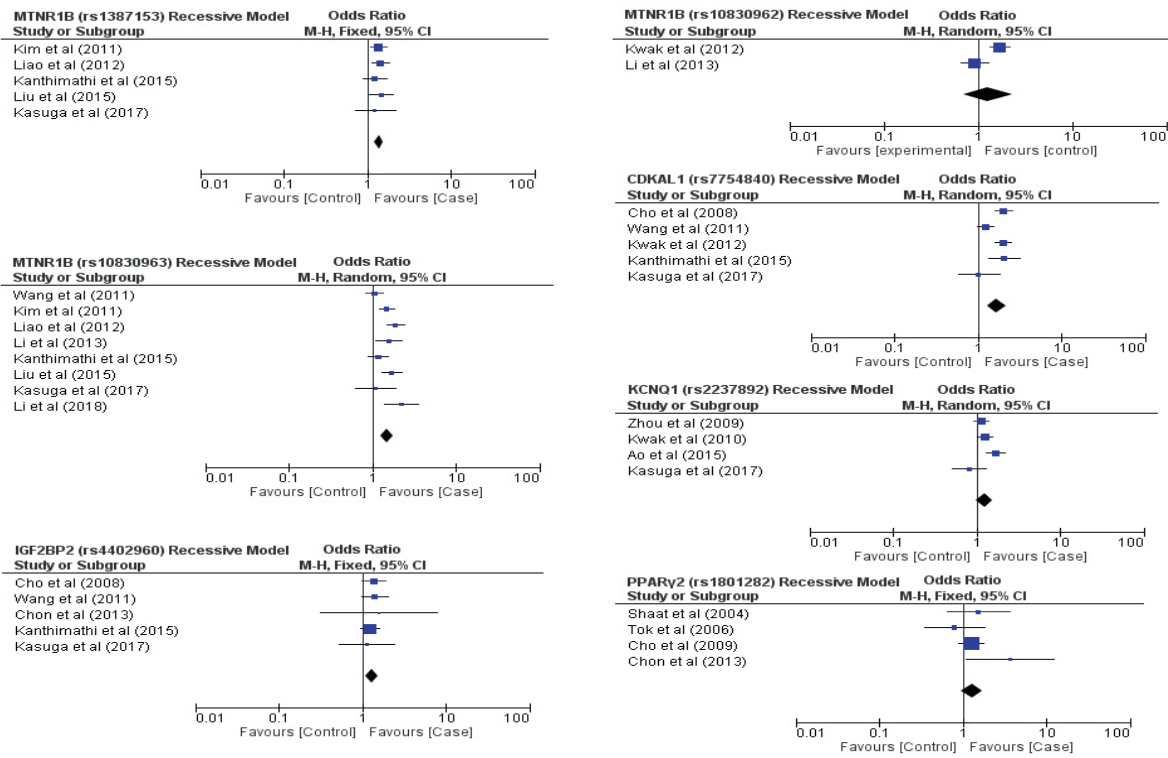

Figure 2B: Forest plot for genetic association of GDM using different genetic models (Recessive model). 

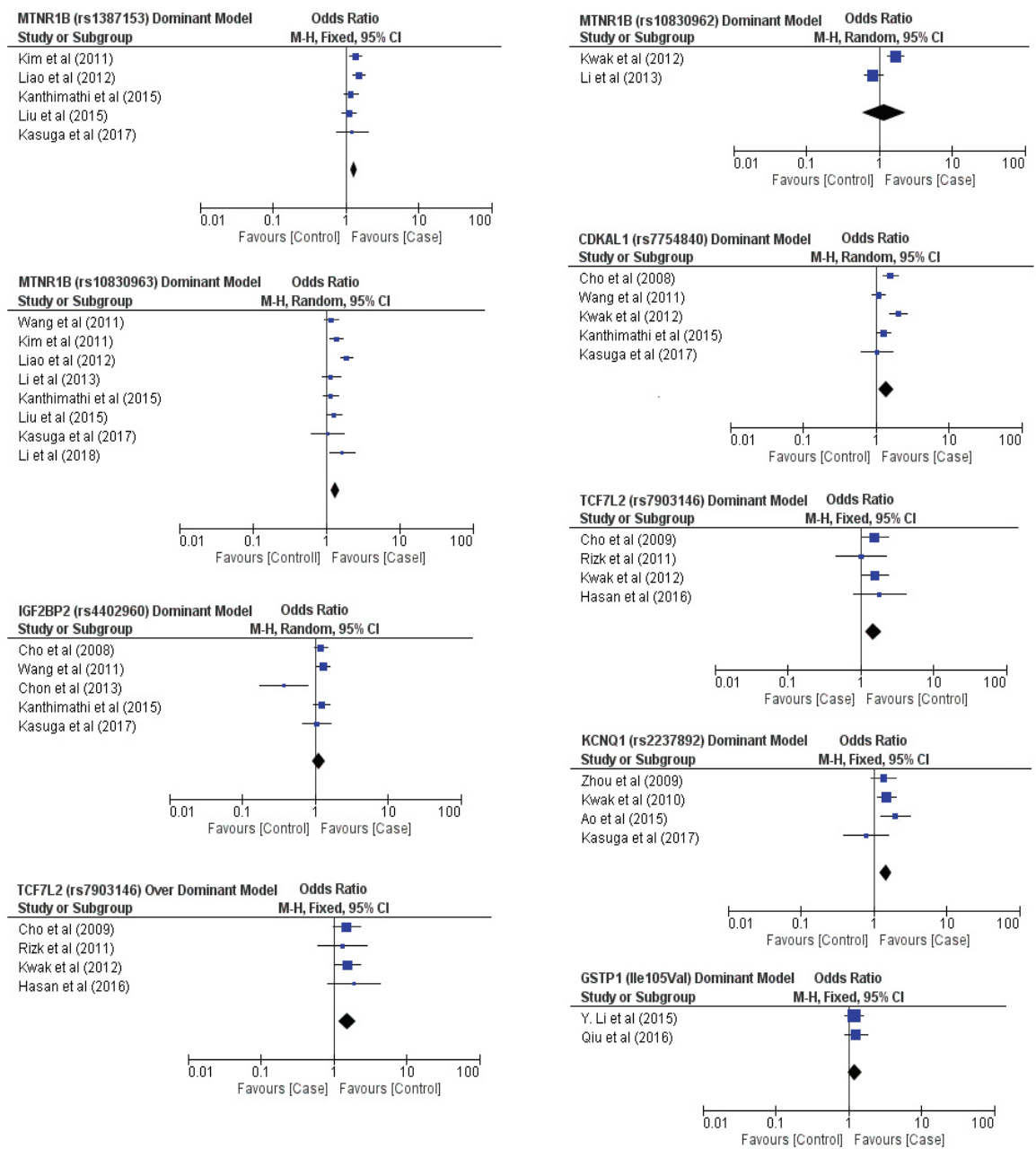

Figure 2C: Forest plot for genetic association of GDM using different genetic models (Dominant model).

\section{Genetic Variants Involved in $\beta$-Cell Function}

\section{Melatonin receptor 1B (MTNR1B)}

Three genetic variants for MTNR1B were analysed. For rs1387153, calculated pooled effects from five studies (Kanthimathi et al. 2015; Kasuga et al. 2017; Kim et al. 2011; Liao et al. 2012; Liu et al. 2016) showed significant association with increased risk of GDM in the allelic genetic model (Figure 2A, OR $=1.24$ [95\% Cl: 1.16, 1.33]; $p<0.00001$; recessive model (Figure 2B, OR $=1.37$ [95\% Cl: 1.20, 1.55]; $p<0.00001$ ); dominant model (Figure 2C, OR $=1.30[95 \% \mathrm{Cl}: 1.17,1.43] ; p<0.00001$ ). The $\mathrm{I}^{2}$ value suggests low heterogeneity and small variation across the studies. Analysis for rs 10830962 demonstrated 
insignificant association with increased risk of GDM, as shown by the allelic model (Figure $2 \mathrm{~A}, \mathrm{G}$ versus $\mathrm{C}$ ) with $\mathrm{OR}=1.16$ [95\% Cl: $0.71,1.90] ; p=0.55$, recessive model (Figure 2B, OR $=1.28$ [95\% Cl: 0.82, 2.37]; $p=0.43$ ) and dominant model (Figure $2 \mathrm{C}, \mathrm{OR}=1.19$ [95\% Cl: 0.59, 2.37]; $p=0.63$ ). In addition, the heterogeneity for the two studies (Kwak et al. 2012; $\mathrm{Li}$ et al. 2013) used in the analysis of this genetic variant is significant $\left(\mathrm{I}^{2}>50 \%\right)$ and thus, random effect model was used. MTNR1B (rs10830963) is the most extensively studied polymorphism for GDM in Asian population, with eight studies (Kanthimathi et al. 2015; Kasuga et al. 2017; Kim et al. 2011; Li et al. 2013; Li et al. 2019; Liao et al. 2012; Liu et al. 2016; Wang et al. 2011) included in this meta-analysis. It shows significant association with increased risk of GDM in allelic (Figure 2A, OR = 1.29 [95\% Cl: 1.15, 1.44]; $p<0.00001$ ), recessive genetic models (Figure $2 \mathrm{~B}, \mathrm{OR}=1.48[95 \% \mathrm{Cl}: 1.24,1.76] ; p<0.0001$ ) and dominant (Figure $2 \mathrm{C}, \mathrm{OR}=1.35[95 \% \mathrm{Cl}: 1.16,1.56] ; p<0.0001$ ) with high heterogeneity. Random effect model was used.

\section{CDK5 regulatory subunit associated protein-like 1 (CDKAL1)}

The association between CDKAL1 (rs7754840) and GDM was investigated in five studies (Cho et al. 2008; Kanthimathi et al. 2015; Kasuga et al. 2017; Kwak et al. 2012; Wang et al. 2011). Our meta-analysis demonstrated that the risk allele $C$ of this SNP is significantly associated with increased risk of GDM (Figure 2A, OR $=1.35[95 \% \mathrm{Cl}: 1.12,1.62] ; p=$ 0.001). The homozygous variant genotype $C C$ showed an even stronger, significant association with GDM in recessive model (Figure 2B, OR $=1.66$ [95\% Cl: $1.28,2.15] ; p=$ 0.0002). Dominant genetic model for this SNP also demonstrated significant association with increased GDM risk (Figure 2C, OR $=1.39[95 \% \mathrm{Cl}: 1.10,1.76] ; p=0.006$ ). The heterogeneity is significant. Hence, we used random effect model.

\section{Insulin-like growth factor 2 mRNA-binding protein 2 (IGF2BP2)}

Five studies (Cho et al. 2008; Chon et al. 2013; Kanthimathi et al. 2015; Kasuga et al. 2017; Wang et al. 2011) were analysed for the association of rs4402960 with increased GDM risks. Allelic model (Figure 2A, T versus $G$ ) and recessive model (Figure 2B, TT versus GG + GT) both showed significant association to GDM with low heterogeneity. The pooled effects for the allelic and recessive models for this polymorphism are OR $=1.18[95 \% \mathrm{Cl}$ : $1.08,1.28] ; p=0.0002$ and $\mathrm{OR}=1.30$ [95\% Cl: 1.10, 1.55]; $p=0.003$, respectively. As for dominant model (Figure 2C, TT + GT versus GG), the heterogeneity across the study is significant $\left(I^{2}=60 \%\right)$. Thus, random effect model was used, resulting in insignificant association with GDM (OR $=1.13$ [95\% Cl: $0.92,1.39] ; p=0.26)$.

\section{Transcription factor-7 like 2 (TCF7L2)}

The association of TCF7L2 (rs7903146) polymorphism with increased risk of GDM was analysed by extracting genotype frequencies data from four studies (Cho et al. 2008; Hasan et al. 2016; Kwak et al. 2012; Rizk 2011). This polymorphism consistently showed strong association with GDM in allelic model T versus C (Figure 2A, OR $=1.41[95 \% \mathrm{Cl}$ : 1.10 , 1.80]; $p=0.006$ ) and dominant model (Figure $2 \mathrm{C}, 1.51$ [95\% Cl: $1.16,1.98] ; p=0.002$ ). In addition, the heterogeneity across these studies is very low $\left(I^{2}<10 \%\right)$. 


\section{Potassium voltage-gated channel, KQT-like subfamily, member 1 (KCNQ1)}

The pooled OR effects from four studies (Ao et al. 2015; Kasuga et al. 2017; Kwak et al. 2010; Zhou et al. 2009) on KNCQ1 (rs2237892) polymorphism revealed insignificant association of this genetic variant with increased susceptibility to GDM. This can be seen in allelic (Figure 2A, C versus T) and recessive model (Figure 2B, with OR $=1.21$ [95\% Cl: $1.00,1.46] ; p=0.05$ and $\mathrm{OR}=1.23$ [95\% Cl: $0.98,1.55] ; p=0.08)$, respectively. These models also demonstrated high heterogeneity. On the contrary, dominant model, with low heterogeneity, showed significant association towards GDM risk (Figure 2C, OR $=1.47$ [95\% Cl: $1.20,1.79] ; p=0.0002)$.

\section{Genetic Variants Involved in Insulin Resistance}

\section{Peroxisome proliferator-activated receptor gamma 2 (PPARY2)}

Collective data from four studies (Cho et al. 2008; Chon et al. 2013; Shaat et al. 2004; Tok et al. 2006) on PPARy2 ( 1 1801282) showed that the wild type allele, instead of risk allele is the minor allele in Asian population. Based on allelic genetic model (Figure 2A, Pro versus Ala) and recessive genetic model (Figure $2 \mathrm{~B}$ ), moderate association to increased risk of GDM is shown by OR $=1.30$ [95\% Cl: $0.98,1.73] ; p=0.07$ and $\mathrm{OR}=1.29$ [95\% Cl: 0.97 , 1.74 ]; $p=0.08$, respectively. However, the $p$-value for both odds ratios is more than 0.05 , rendering it insignificant.

\section{Genetic Variants Involved in Oxidative Stress}

\section{Glutathione S-transferase (GST)}

Two studies (Tok et al. 2006; Li et al. 2015) on GSTP1 (rs1695) and three studies (Li et al. 2015; Orhan et al. 2014; Qiu, Xu and Zhang 2016) on GSTM1 and GSTT1 were analysed in our study. GSTP1 ( $r$ 1695) demonstrated significant association with GDM only in allelic genetic model (Figure 2A, OR $=1.19$ [95\% Cl: 1.10, 1.41]; $p=0.05$ ) with zero heterogeneity, whereas the dominant genetic model shows insignificant association with increased risk of GDM (Figure 2C, OR = 1.22 [95\% Cl: 0.97, 1.54]; $p=0.09$ ). As for GSTM1 and GSTT1 polymorphism, the deletion of these genes are strongly and significantly associated with GDM, as depicted by Figure 2A, OR $=1.72[95 \% \mathrm{Cl}: 1.37,2.16 ; p<0.00001$ and Figure $2 \mathrm{~A}$, $\mathrm{OR}=1.51[95 \% \mathrm{Cl}: 1.01,2.26] ; p=0.04$, respectively. However, only GSTM1 showed zero heterogeneity across the studies, whereas GSTT1 has substantial heterogeneity $\left(I^{2}=54 \%\right)$.

\section{Publication Bias and Sensitivity Test}

Funnel plot was used to identify potential publication biases of the studies. The shapes of the funnel plots appeared to be symmetrical, suggesting that no obvious publication bias is present. Sensitivity analysis was done by omitting one study at a time to determine the consistency of the results. 


\section{DISCUSSION}

In this meta-analysis, 11 genetic variants were investigated to find their association with increased GDM susceptibility in the Asian population. Out of the 21 studies analysed, 20 studies were conducted based on candidate gene approach; one was a GWAS by Kwak et al. (2012). Overall, this meta-analysis found significant association of increased risk to GDM susceptibility with nine genetic variants: rs1387153 and rs10830963 from MTNR1B, rs7754840 (CDKAL1), rs4402960 (IGF2BP2), rs2237892 (KCNQ1), rs7903146 (TCF7L2), GSTM1, GSTT1 and GSTP1 (rs1695) under different combination of genetic models. However, only rs1387153, 4402960, rs2237892, rs7903146, GSTM1 and GSTP1 (rs1695) have low heterogeneity across the studies. Other SNPs with significant association but high heterogeneity $\left(I^{2}>50 \%\right)$ were analysed using random effect model. The remaining SNPs in this analysis, MTNR1B (rs108309062) and PPARY2 (rs1801282) have insignificant associations with GDM in Asian populations.

GDM and DM2 are believed to share the same pathogenesis such as insulin resistance, impaired $\beta$-cell function, abnormal glucose utilisation and oxidative stress (Lauenborg et al. 2009). Insulin resistance is caused by insulin-desensitising placental hormones and hormonal changes due to increased maternal adiposity such as cortisol, human placental lactogen, prolactin and oestrogen. Predisposition to chronic low-grade inflammation will increase the concentration of reactive oxygen species (ROS), deteriorating $\beta$-cell insufficiency, and by extension, glucose tolerance impairment (Law and Zhang 2017).

Melatonin is a hormone secreted mainly from pineal glands and primarily functions to maintain circadian rhythm. Melatonin inhibits cyclic adenosine monophosphate (cAMP) pathway that stimulates secretion of insulin, which are mediated through G-protein coupled Melatonin receptor 1B (Zhang et al. 2014). Secretion of melatonin peaks during the night, while secretion of insulin is reduced, to compensate the lack of glucose in the body during overnight fasting. Overexpression of MTNR1B exaggerates the inhibition of insulin release (Tuomi et al. 2016). During pregnancy, MTNR1B is likely to be involved in the regulation of glucose homeostasis.

Individuals with the risk allele T of rs 1387153 showed $24 \%$ increased risk for GDM compared to those who do not possess it. TT genotype further emphasis this finding with OR that suggest strong association to increased GDM risk. This conforms to the findings by Zhang et al. (2014) and Gao et al. (2016) among the Caucasian and Asian populations. As for rs10830962, the result for this analysis is not considered to be representative for the Asian population. Women with allele G and GG genotype of rs10830963 for MTNR1B recorded $29 \%$ and $48 \%$ increased risk for GDM, respectively. Dominant genetic model also showed significant association to GDM. Our finding correlates with the study by Zhang et al. (2014) and Gao et al. (2016) that also found significant, positive association of this genetic variant to increased GDM susceptibility. Meanwhile, wild type allele $C$ has protective effect against GDM.

Animal studies showed that in obese mice, CDKAL1 mRNA levels were reduced and the mitochondrial functions were impaired, leading to inefficient energy expenditure by the cells. In this meta-analysis, SNP rs 7754840 was replicated in five studies (Cho et al. 2008; Kanthimathi et al. 2015; Kasuga et al. 2017; Kwak et al. 2012; Wang et al. 2011 ) in Asian populations. Pooled effects showed that risk allele $C$ and genotype CC show significant positive association to GDM. Meanwhile, G allele and GG genotype do not show association to GDM and hence, are deemed as protective. Dominant genetic model (CC + CG versus $G G$ ) shows significant association to increased GDM risk with high heterogeneity. A meta-analysis by Gao et al. (2016) and a cohort study by Aris

Malay J Pharm Sci, Vol. 19, No. 2 (2021): 131-152 
et al. (2011) also support significant association of this genetic variant with increased risk to GDM susceptibility. However, a study by Noury et al. (2018) on pregnant women in Egypt revealed insignificant association to GDM.

For risk allele T of rs4402960, four out of the five studies that we analysed showed that it has association with increased risk for GDM. Only study by Chon et al. (2013) showed negative association of this allele. Pooled effects obtained from allelic and recessive genetic models, however, showed significant positive associations to GDM susceptibility. As for dominant model, due to high heterogeneity, the analysis was done under random effect, resulting in insignificant association towards increased risk of GDM. Subgroup analysis revealed that there was no difference in terms of association to GDM across populations. Meta-analysis by Mao, Li and Gao (2012) which comprised of both Asian and Caucasian populations supports our finding with significant positive association of this genetic variant to increased risk for GDM under allelic model. Meanwhile, a study in Danish population (Lauenborg et al. 2009) found insignificant association.

TCF7L2 (rs7903146) is a transcriptional regulator that is involved in stimulating the hyperplasia of pancreatic B-cells and the production of incretin hormone glucagon-like peptide-1 in enterocytes. This polymorphism modifies the sensitivity of pancreatic B-cells to incretin and subsequently insulin secretion. The risk T-allele was reported to have association with increased TCF7L2 expression, causing reduction of insulin production and secretion. It showed a consistent and strong association with impaired glucose tolerance and $\beta$-cell function across different populations, such as the Caucasians and African-American descendants. In our meta-analysis, the pooled effects of four studies showed strong, significant association of this SNP to increased risk of GDM susceptibility in allelic, dominant and over-dominant genetic models. These models demonstrated low heterogeneity, indicating that the results are highly reliable. Our findings correlate with the studies by Lauenborg et al. (2009), Wu et al. (2016) and Lin et al. (2016).

KCNQ1 is involved in coding the pore-forming subunit of a $\mathrm{K}+$ voltage-gated channel, mainly in cardiac muscle that is responsible for the repolarisation of the action potential. Its mutation is associated with long QT interval and familial atrial fibrillation. KCNQ1 is also expressed in tissues including brain, adipose and pancreas. The risk allele will cause impaired insulin secretion, and therefore is associated in higher risk of developing type-2 diabetes and GDM. In this meta-analysis, KNCQ1 (rs2237892) found insignificant association of this genetic variant to increased GDM risk, under allelic ( $C$ versus $T)$ and recessive models. On the other hand, dominant genetic model (CC + CT versus TT) showed significant positive association with GDM. A genetic association study by Shin et al. (2010) in 930 Korean females with GDM revealed that rs2237892 might represent genetic risk factors for GDM. A study in the Mexican women by Huerta-Chagoya et al. (2015) also found negative association of wild-type T allele with GDM, suggesting protective effect. It is worth noting that while $T$ allele is protective, the risk allele $C$ is the major allele for this SNP, making it a prevalent gene associated with GDM in the population.

Activation of PPARy2 helps to improve insulin action (Cho et al. 2008; Tok et al. 2006). In this study, the major allele $C$ is also a risk allele, as evidenced by the OR value in allelic and recessive genetic model. However, the $p$-value is more than 0.05 , rendering it insignificant. The studies on Scandinavian populations (Lauenborg et al. 2009) and a metaanalysis by Mao, Li and Gao (2012) also showed insignificant association of this genetic variant with GDM. We found no association of minor allele $G$ with susceptibility of GDM. The meta-analysis by Wu et al. (2016) supports this finding.

GST is an enzyme encoded by GST gene family that primarily functions as antioxidants. It functions are to: a) detoxify environmental toxicants and ROS mediated cell injury in the body, b) catalyse neutralisation of the harmful compounds and c) prevent DNA

Malay J Pharm Sci, Vol. 19, No. 2 (2021): 131-152 
damage (Li et al. 2015). Complete GST family comprised of 16 genes in six subfamilies. In this study, we studied the association of increased risk of GDM to three subfamilies of this gene which are pi (GSTP), mu (GSTM) and theta (GSTT).

GSTP1 enzyme plays an important role in biotransformation and bioactivation of certain environmental pollutants and other diol epoxides of polycyclic aromatic hydrocarbons. It provides protection against oxidative stress by catalysing the detoxification of base propanols that arise from DNA oxidation. The GSTP1 (rs1695) polymorphism at codon 105 (exon 5) results in an amino acid substitution of isoleucine by valine.

Similar to our study, Li et al. (2015) and Qiu, Xu and Zhang (2016) found that GSTP1 (rs1695) polymorphism influences the risk of GDM. The risk allele (G; Val) was also found to be associated with an increased risk for GDM in our study and in Egypt (Amer et al. 2012). Another study also showed significant association, suggesting this polymorphism to be screened in the North Indian population to determine diabetic risk (Bid et al. 2010).

GSTM1 and GSTT1 are involved in catalysing the conjugation of glutathione to a variety of hydrophobic and electrophilic substrates and carcinogens (Li et al. 2015). Several studies had reported that subjects who have GSTM1 NULL genotype and GSTT1 NULL genotype are susceptible to gestational diabetes mellitus (Li et al. 2015; Orhan et al. 2014; Qiu, Xu and Zhang 2016). For GSTM1 NULL genotype, our result was consistent with the findings from the Chinese ( $\mathrm{Li}$ et al. 2015; Qiu, Xu and Zhang 2016) but different from the Turkish population (30). As for GSTT1 NULL genotype, our finding is only supported by the study by Li et al. (2015), whereby the other two studies (Orhan et al. 2014; Qiu, Xu and Zhang 2016) found insignificant association of null GSTT1 to increased risk of GDM.

Homozygous deletion of either GSTM1 or GSTT1 locus was found to cause loss of function on enzymatic activity of GST. In turn, it may impair the capacity of defence against oxidative stress (Yalin et al. 2007), aggravating the damage caused by ROS to pancreatic $\beta$-cells, causing reduction of insulin production. Polymorphism of these genes, whether alone or as combination, influence the increased risk of DM2 in North Indian population (Bhandari 2014). In addition, GSTM1 may be a useful marker for DM prediction in Turkish population (Bhandari 2014). However, Zaki et al. (2015) found no significant association of GSTM1 and GSTT1 null genotypes for the diabetic Egyptian. The discrepancies on studies about these genes can be attributed to the small number of studies focusing on diabetes condition among the Asians.

Potential publication bias of the 21 journals used in this meta-analysis were assessed using Funnel plot. We found that there is no obvious publication bias, based on the symmetrical shape of the plots. Egger's test is another tool used to assess publication bias but we were unable to carry it out because RevMan 5.3 package does not offer such test. Subgroup analysis based on ethnicity and genotyping method was done for CDKAL1 (rs7754840), MTNR1B (rs10830963) and GTTT1. CDKAL1 (rs7754840) showed subgroup effect for ethnicity but not on genotyping method. MTNR1B (rs10830963) showed no subgroup effect with moderate unexplained heterogeneity and uneven covariate distribution. GTT1 showed no subgroup effect at all.

The major limitation of this meta-analysis was the insufficient number of studies in some of the SNPs in Asian population. Two of the genetic variants in this analysis were only discussed in two studies and another two SNPs in three studies. It is hard to draw conclusion based on a few studies, especially when the studies show contradicting results due to different ethnicity. Other than that, small sample size affects the $p$-value and heterogeneity of the results, thus making the analysis lack reliability and credibility to represent the population. To confirm the relationship of the genes with GDM, more studies on the association of the genes with GDM in Asian population, with larger sample size are required. Furthermore, in this meta-analysis, we did not consider confounding factors 
such as maternal age, BMI, history of diabetes, lifestyle during pregnancy. Finally, as there were not many studies done in Asian population, there were lack of data, hence it cannot represent for the whole Asian population. Further studies including subjects at other parts of Asia, such as the Southeast Asia, where GDM prevalence is reported to be high should be carried out to better understand the association of these genetic variants with susceptibility of GDM.

\section{CONCLUSION}

Nine genetic variants were found to have significant association with increased susceptibility for GDM in Asian population. Identification of these genetic risk variants can be used to tailor personalised preventive measures and therapeutic intervention. This could enable physicians to provide better healthcare plan and help the patients to avoid pathological conditions that could be detrimental at their later stage of life.

\section{ACKNOWLEDGEMENTS}

We would like to express our appreciation and gratitude for all individuals who were involved directly or indirectly in conducting this research, especially from the Integrative Pharmacogenomics Institute (iPROMISE), Universiti Teknologi MARA (UiTM), Malaysia.

\section{REFERENCES}

AMER, M. A., GHATTAS, M. H., ABO-ELMATTY, D. M. \& ABOU-EL-ELA, S. H. (2012) Evaluation of glutathione S-transferase P1 genetic variants affecting type-2 diabetes susceptibility and glycemic control, Archives of Medical Science, 8(4): 631-636. https://doi. org/10.5114/aoms.2012.30286

AO, D., WANG, H. J., WANG, L. F., SONG, J. Y., YANG, H. X. \& WANG, Y. (2015) The rs2237892 polymorphism in KCNQ1 influences gestational diabetes mellitus and glucose levels: A case-control study and meta-analysis, PLOS ONE, 10(6): 1-11. https://doi. org/10.1371/journal.pone.0128901

ARIS, N. M., ISMAIL, N. M., MAHDY, Z. A., AHMAD, S., NAIM, N. M., SIRAJ, H. H. et al. (2011) An analysis of targeted single nucleotide polymorphisms for the risk prediction of gestational diabetes mellitus in a cohort of Malaysian patients, Asia-Pacific Journal of Molecular Medicine, 1(1): 1-8.

BID, H. K., KONWAR, R., SAXENA, M., CHAUDHARI, P., AGRAWAL, C. G. \& BANERJEE, M. (2010) Association of glutathione S-transferase (GSTM1, T1 and P1) gene polymorphisms with type 2 diabetes mellitus in North Indian population, Journal of Postgraduate Medicine, 56(3): 176-181. https://doi.org/10.4103/0022-3859.68633

BHANDARI, M. (2014) Association of the glutathione s-transferase (GST) gene polymorphisms with type 2 diabetes mellitus risk factors in North Indian population. Scholarly Journal of Scientific Research and Essay (SJSRE), 3(6): 77-82.

Malay J Pharm Sci, Vol. 19, No. 2 (2021): 131-152 
BEER, N. L. \& MCCARTHY, M. I. (2014) Genome-wide association studies in type 2 diabetes, Frontiers in Diabetes Genetics in Diabetes, 23: 1-13. https://doi. org/10.1159/000362463

CHO, Y. M., KIM, T. H., LIM, S., CHOI, S. H., SHIN, H. D., LEE, H. K. et al. (2008) Type 2 diabetes-associated genetic variants discovered in the recent genome-wide association studies are related to gestational diabetes mellitus in the Korean population, Diabetologia, 52(2): 253-261. https://doi.org/10.1007/s00125-008-1196-4

CHON, S. J., KIM, S. Y., CHO, N. R., MIN, D. L., HWANG, Y. J. \& MAMURA, M. (2013) Association of variants in PPARY2, IGF2BP2, and KCNQ1 with a susceptibility to gestational diabetes mellitus in a Korean population, Yonsei Medical Journal, 54(2): 352-357. https://doi.org/10.3349/ymj.2013.54.2.352

GAO, F., WANG, G., FU, D. \& GUO, N. (2016) TNF-a (rs1800629), CDKAL1 (rs7754840, rs7756992), MTNR1B (rs10830963, rs1387153) polymorphisms were linked to gestational diabetes mellitus (GDM) risks: Based on an updated meta-analysis, International Journal of Clinical and Experimental Medicine, 9(8): 15400-15413.

HASAN, M., HASANAT, M. A., NADIM-HASAN, K., PANTHI, S., AKTAR, Y., SULTANA, N. et al. (2016) TCF7L2 gene rs7903146 polymorphism is observed in gestational diabetes mellitus in Bangladesh, Integrative Obesity and Diabetes, 2(4). https://doi.org/10.15761/ IOD.1000155

HUERTA-CHAGOYA, A., VÁZQUEZ-CÁRDENAS, P., MORENO-MACÍAS, H., TAPIAMARURI, L., RODRÍGUEZ-GUILLÉN, R., LÓPEZ-VITE, E. et al. (2015) Genetic determinants for gestational diabetes mellitus and related metabolic traits in Mexican women, Plos ONE, 10(5): e0126408. https://doi.org/10.1371/journal.pone.0126408

KANTHIMATHI, S., CHIDAMBARAM, M., LIJU, S., BHAVADHARINI, B., BODHINI, D., PRAKASH, V. G. et al. (2015) Identification of genetic variants of gestational diabetes in South Indians, Diabetes Technology \& Therapeutics, 17(7): 462-467. https://doi. org/10.1089/dia.2014.0349

KASUGA, Y., HATA, K., TAJIMA, A., OCHIAI, D., SAISHO, Y., MATSUMOTO, T. et al. (2017) Association of common polymorphisms with gestational diabetes mellitus in Japanese women: A case-control study, Endocrine Journal, 64(4): 463-475. https://doi. org/10.1507/endocrj.EJ16-0431

KIM, J. Y., CHEONG, H. S., PARK, B.-L., BAIK, S. H., PARK, S., LEE, S. W. et al. (2011) Melatonin receptor $1 \mathrm{~B}$ polymorphisms associated with the risk of gestational diabetes mellitus, BMC Medical Genetics, 12(1): 82. https://doi.org/10.1186/1471-2350-12-82

KWAK, S. H., KIM, T. H., CHO, Y. M., CHOI, S. H., JANG, H. C. \& PARK, K. S. (2010) Polymorphisms in KCNQ1 are associated with gestational diabetes in a Korean population, Hormone Research in Paediatrics, 74(5): 333-338. https://doi. org/10.1159/000313918 
KWAK, S. H., KIM, S.-H., CHO, Y. M., GO, M. J., CHO, Y. S., CHOI, S. H. et al. (2012) A genome-wide association study of gestational diabetes mellitus in Korean women, Diabetes, 61(2): 531-541. https://doi.org/10.2337/db11-1034

LAUENBORG, J., GRARUP, N., DAMM, P., BORCH-JOHNSEN, K., JøRGENSEN, T., PEDERSEN, O. et al. (2009) Common type 2 diabetes risk gene variants associate with gestational diabetes, The Journal of Clinical Endocrinology and Metabolism, 94(1): 145150. https://doi.org/10.1210/jc.2008-1336

LAW, K. P. \& ZHANG, H. (2017) The pathogenesis and pathophysiology of gestational diabetes mellitus: Deductions from a three-part longitudinal metabolomics study in China, Clinica Chimica Acta, 468: 60-70. https://doi.org/10.1016/j.cca.2017.02.008

LI, C., QIAO, B., ZHAN, Y., PENG, W., CHEN, Z. J., SUN, L. et al. (2013) Association between genetic variations in MTNR1A and MTNR1B genes and gestational diabetes mellitus in han chinese women, Gynecologic and Obstetric Investigation, 76(4): 221-227. https://doi.org/10.1159/000355521

LI, C., ZHOU, Y., QIAO, B., XU, L., LI, Y. \& LI, C. (2019) Association between a melatonin receptor $1 \mathrm{~b}$ genetic polymorphism and its protein expression in gestational diabetes mellitus, Reproductive Sciences, 26(10): 1382-1388. https://doi.org/10.1177/1933719118765983

LI, Y., LI, S., ZHAI, Q., HAI, J., WANG, D., CAO, M. et al. (2015) Association of GSTs polymorphisms with risk of gestational diabetes mellitus, International Journal of Clinical and Experimental Pathology, 8(11): 15191-15197.

LIAO, S., LIU, Y., TAN, Y., GAN, L., MEI, J., SONG, W. et al. (2012) Association of genetic variants of melatonin receptor $1 \mathrm{~B}$ with gestational plasma glucose level and risk of glucose intolerance in pregnant Chinese women, PLoS ONE, 7(7): e40113. https://doi.org/10.1371/ journal.pone.0040113

LIN, P., LIN, W., YEH, Y. \& WUNG, S. (2016) Transcription factor 7-like 2 (TCF7L2) rs7903146 polymorphism as a risk factor for gestational diabetes mellitus: A metaanalysis, Plos ONE, 11(4): e0153044. https://doi.org/10.1371/journal.pone.0153044

LIU, Q., HUANG, Z., LI, H., BAI, J., LIU, X. \& YE, H. (2016) Relationship between melatonin receptor 1B (rs10830963 and rs1387153) with gestational diabetes mellitus: A case-control study and meta-analysis, Archives of Gynecology and Obstetrics, 294(1): 55-61. https://doi. org/10.1007/s00404-015-3948-y

LOGAKODIE, S., AZAHADI, O., FUZIAH, P., NORIZZATI, B., TAN, S. F., ZIENNA, Z. et al. (2017) Gestational diabetes mellitus: The prevalence, associated factors and foetomaternal outcome of women attending antenatal care, The Official Journal of the Academy of Family Physicians of Malaysia, 12(2): 9-17.

LOWE, W. L., SCHOLTENS, D. M., SANDLER, V. \& HAYES, M. G. (2016) Genetics of gestational diabetes mellitus and maternal metabolism, Current Diabetes Reports, 16(2). https://doi.org/10.1007/s11892-015-0709-z

Malay J Pharm Sci, Vol. 19, No. 2 (2021): 131-152 
MAO, H., LI, Q. \& GAO, S. (2012) Meta-analysis of the relationship between common type 2 diabetes risk gene variants with gestational diabetes mellitus, PLOS ONE, 7(9): e45882. https://doi.org/10.1371/journal.pone.0045882

NOURY, A. E., AZMY, O., ALSHARNOUBI, J., SALAMA, S., OKASHA, A. \& GOUDA, W. (2018) Variants of CDKAL1 rs7754840 (G/C) and CDKN2A/2B rs10811661 (C/T) with gestational diabetes: Insignificant association, BMC Research Notes, 11(1): 181. https://doi.org/10.1186/s13104-018-3288-7

ORHAN, O., ATALAY, M., ORHAN, F., KARKUCAK, M., DEMIR, B., YAKUT, T. et al. (2014) Glutathione S-transferase M1 and T1 gene polymorphisms are not associated with increased risk of gestational diabetes mellitus development, West Indian Medical Journal, 63(4): 300-306. https://doi.org/10.7727/wimj.2013.128

QIU, Y. H., XU, Y. L. \& ZHANG, W. H. (2016) Effect of GSTM1, GSTT1, and GSTP1 Ile105Val polymorphisms on susceptiblity to gestational diabetes mellitus, Genetics and Molecular Research, 15(2): gmr.15027711. https://doi.org/10.4238/gmr.15027711

RIZK, N. (2011) The associations of transcription factor 7-like 2 [TCF7L2] gene with gestational diabetes mellitus in State of Qatar, Qatar Foundation Annual Research Forum Proceedings, 2011(1): BMP8. https://doi.org/10.5339/qfarf.2011.bmp8

RODRIGO, N. \& GLASTRAS, S. (2018) The emerging role of biomarkers in the diagnosis of gestational diabetes mellitus, Journal of Clinical Medicine, 7(6): 120. https://doi.org/10.3390/ jcm7060120

SHAAT, N., EKELUND, M., LERNMARK, À., IVARSSON, S., NILSSON, A., PERFEKT, R. et al. (2004) Genotypic and phenotypic differences between Arabian and Scandinavian women with gestational diabetes mellitus, Diabetologia, 47(5): 878-884. https://doi. org/10.1007/s00125-004-1388-5

SHIN, H. D., PARK, B. L., SHIN, H. J., KIM, J. Y., PARK, S., KIM, B. et al. (2010) Associations of KCNQ1 polymorphisms with gestational diabetes mellitus in Korean women, The Journal of Clinical Endocrinology \& Metabolism, 95(1): 445-449. https://doi.org/10.1210/jc.20091393

StUeBE, A., NGUYEN, T., HERRING, A., NORTH, K., SIEGA-RIZ, A. \& WISE, A. (2014) Maternal Genotype and Gestational Diabetes, American Journal of Perinatology, 31(1): 69-76. https://doi.org/10.1055/s-0033-1334451

TAN, P. C., LING, L. P. \& OMAR, S. Z. (2007) Screening for gestational diabetes at antenatal booking in a Malaysian university hospital: The role of risk factors and threshold value for the 50-g glucose challenge test, The Australian and New Zealand Journal of Obstetrics and Gynaecology, 47(3): 191-197. https://doi.org/10.1111/j.1479-828X.2007.00717.x

TOK, E. C., ERTUNC, D., BILGIN, O., ERDAL, E. M., KAPLANOGLU, M. \& DILEK, S. (2006) PPAR-y2 Pro12Ala polymorphism is associated with weight gain in women with gestational diabetes mellitus, European Journal of Obstetrics and Gynecology and Reproductive Biology, 129(1): 25-30. https://doi.org/10.1016/j.ejogrb.2006.03.016 
TUOMI, T., NAGORNY, C. L., SINGH, P., BENNET, H., YU, Q., ALENKVIST, I. et al. (2016) Increased melatonin signaling is a risk factor for type 2 diabetes, Cell Metabolism, 23(6): 1067-1077. https://doi.org/10.1016/j.cmet.2016.04.009

WANG, Y., NIE, M., LI, W., PING, F., HU, Y., MA, L. et al. (2011) Association of six single nucleotide polymorphisms with gestational diabetes mellitus in a Chinese population, PLoS ONE, 6(11): e26953. https://doi.org/10.1371/journal.pone.0026953

WATANABE, R. M., BLACK, M. H., XIANG, A. H., ALlAYEE, H., LAWRENCE, J. M. \& BUCHANAN, T. A. (2007) Genetics of gestational diabetes mellitus and type 2 diabetes, Diabetes Care, 30(Supplement 2): S134-S140. https://doi.org/10.2337/dc07-s205

WU, L., CUI, L., TAM, W. H., MA, R. C. \& WANG, C. C. (2016) Genetic variants associated with gestational diabetes mellitus: A meta-analysis and subgroup analysis, Scientific Reports, 6(1): 30539. https://doi.org/10.1038/srep30539

YALIN, S., HATUNGIL, R., TAMER, L., ATES, N. A., DOGRUER, N., YILDIRIM, H. et al. (2007) Glutathione S-transferase gene polymorphisms in Turkish patients with diabetes mellitus, Cell Biochemistry and Function, 25(5): 509-513. https://doi.org/10.1002/cbf.1339

ZAKI, M. A., MOGHAZY, T. F., EL-DEEB, M. M., MOHAMED, A. H. \& MOHAMED, N. A. (2015) Glutathione S-transferase M1, T1 and P1 gene polymorphisms and the risk of developing type 2 diabetes mellitus in Egyptian diabetic patients with and without diabetic vascular complications, Alexandria Journal of Medicine, 51(1): 73-82. https://doi. org/10.1016/j.ajme.2014.03.003

ZHANG, Y., SUN, C., HU, X. \& ZHAO, Y. (2014) Relationship between melatonin receptor $1 \mathrm{~B}$ and insulin receptor substrate 1 polymorphisms with gestational diabetes mellitus: $\mathrm{A}$ systematic review and meta-analysis, Scientific Reports, 4(1): 6113. https://doi.org/10.1038/ srep06113

ZHOU, Q., ZHANG, K., LI, W., LIU, J. T., HONG, J., QIN, S. W. et al. (2009) Association of KCNQ1 gene polymorphism with gestational diabetes mellitus in a Chinese population, Diabetologia, 52(11): 2466-2468. https://doi.org/10.1007/s00125-009-1500-y

ZHU, Y. \& ZHANG, C. (2016) Prevalence of gestational diabetes and risk of progression to type 2 diabetes: A global perspective, Current Diabetes Reports, 16(1): 7. https://doi. org/10.1007/s11892-015-0699-x 